\title{
Disease Incidence-Severity Relationships on Leaflets, Leaves, and Fruit in the Pecan-Venturia effusa Pathosystem
}

\author{
Clive H. Bock, ${ }^{1, \dagger}$ and Kuo-Szu Chiang ${ }^{2}$ \\ ${ }^{1}$ USDA-ARS-SEFTNRL, Byron, GA 31008 \\ ${ }^{2}$ Division of Biometrics, Department of Agronomy, National Chung Hsing University, Taichung, Taiwan
}

\begin{abstract}
The most destructive disease of pecan in the southeastern United States is scab, caused by Venturia effusa. Incidence (I)-severity (S) relationships have not previously been characterized in this pathosystem, but incidence measures can save time and should have higher accuracy compared with estimates of severity. Ten scab-susceptible cultivars and seedling trees were assessed for I and S of scab on fruit (1,972 trees) and foliage (compound leaves and leaflets, 1,129 trees) between 2010 and 2014. Samples were assessed on a tree basis, and sample size ranged from 10 to 100 specimens per tree. The range in mean I and $\mathrm{S}$ was different depending on the organ (fruit $\mathrm{I}=0$ to $100 \%, \mathrm{~S}=0$ to $100 \%$; compound leaves and leaflets, $\mathrm{I}=0$ to $100 \%, \mathrm{~S}=0-10.1 \%$, respectively). However, mean I could be $100 \%$ at a mean $\mathrm{S}<2.0 \%$ for fruit, compound leaves, and leaflets. Both I and S data were transformed by complementary

and leaflets $\left(P \leq 0.0001, \mathrm{R}^{2}=0.91\right)$ for all cultivars. The regression analysis showed significant effects of cultivar and year on the relationship between I and S; therefore, separate analyses were performed for each cultivar and year. Back-transformed predicted severity values showed that the differences among cultivars and years were negligible at severity $<80 \%$, and were generally numerically small at severity $>80 \%$. The observation that low severity persists until a high incidence of scab is achieved may limit the ability of incidence data to clearly differentiate treatment effects, even when based on the CLL transformation. But if found to be effective, and if used, it would reduce the labor requirements and result in more accurate data being obtained, as incidence estimates do not tend to suffer from the same subjective biases as do visual estimates of severity.
\end{abstract} $\log -\log$ prior to linear regression analysis. A linear regression model described the relationship between transformed I and $\mathrm{S}$ per tree for fruit $\left(P \leq 0.0001, \mathrm{R}^{2}=0.61\right)$, compound leaves $\left(P \leq 0.0001, \mathrm{R}^{2}=0.82\right)$,
Keywords: tree nuts, disease management, epidemiology, disease development and spread
Pecan scab (Venturia effusa (G. Winter) Rossman \& W.C. Allen [syn. Fusicladium effusum (G. Winter), Rossman et al. 2016]) is a hemibiotrophic fungus that can cause severe yield loss in pecan (Carya illinoinensis (Wangenh.) K. Koch) in the southeastern United States and elsewhere (Bock et al. 2017a). The scab fungus can infect young, expanding foliage, shoots, and fruit, with impact on photoassimilation (Gottwald and Wood 1985). Infection of fruit can lead to abortion, poor kernel filling, reduced nut/kernel size, and poorquality kernel composition (Gottwald and Bertrand 1983; Stevenson and Bertrand 2001). Many of the more popular cultivars are scab susceptible (Goff et al. 2003) and continue to be widely planted (Wells 2014).

The fungus is known to be genetically variable (Bock et al. 2017b) and exhibits pathogenic variability (Conner and Stevenson 2004). Thus, some cultivars that were previously resistant have succumbed

\section{${ }^{\dagger}$ Corresponding author: C. H. Bock; Clive.Bock@ars.usda.gov}

This article reports the results of research only. Mention of a trademark or proprietary product is solely for the purpose of providing specific information and does not constitute a guarantee or warranty of the product by the U.S. Department of Agriculture and does not imply its approval to the exclusion of other products that may also be suitable.

Funding: The research was supported through the USDA-Agricultural Research Service project 6606-21220-011-00D, and through grants from the Georgia Commodity Commission for Pecans.

*The $\boldsymbol{e}$-Xtra logo stands for "electronic extra" and indicates that one supplementary figure and two supplementary tables are published online.

The author(s) declare no conflict of interest.

Accepted for publication 19 May 2019.

This article is in the public domain and not copyrightable. It may be freely reprinted with customary crediting of the source. The American Phytopathological Society, 2019. to adaptability of the pathogen (Goff et al. 1996). The trees are long-lived, with orchards often being several decades old. Fungicides are widely applied to control scab (Bock et al. 2017a). Control typically requires $3-18$ cover sprays of several classes of fungicides when tissues are susceptible and conditions are conducive to infection (Gottwald 1985; Sparks et al. 2009; and Brenneman et al. 1999; Turechek and Stevenson 1998). Although fungicides can provide effective control of scab, they are expensive, and control is often less than desired. Furthermore, fungicides might reduce photoassimilation (Wood and Bock 2018), and there are burgeoning issues with resistance to several classes of these fungicides (Stevenson et al. 2015). The use of resistant cultivars (Bock et al. 2017a), hedge pruning to reduce tree height (Bock et al. 2017c), or aerial application (Bertrand and Brenneman 2001) of fungicide can help manage the disease, but scab remains a threat, and in average and severe epidemic years the disease will cause yield loss.

Disease assessments are a basic need to most research efforts on pecan and other crops (Bock et al. 2010a). This is true in relation to comparing germplasm for disease susceptibility, or comparing fungicides or various other treatments for disease management (Bock et al. 2012, 2016), or to ascertain yield impacts (Gottwald and Bertrand 1983; Stevenson and Bertrand 2001). Currently, both disease severity (the amount of plant tissue diseased) and incidence (the number of units diseased) measurements are taken when assessing scab, but disease severity estimates are time consuming (Seem and Gilpatrick 1980; Seem 1984), and there are inevitable accuracy issues with visual estimates of disease severity (Bock et al. 2008, 2016), which can result in a type II error (Bock et al. 2010b). Yet disease severity is often the variable that is of most importance or interest in a particular experimental situation (Paul et al. 2005). If the relationship between incidence and severity can be defined, it can facilitate the determination of disease intensity. Thus, by virtue of disease incidence counts being quicker, more accurate and straight-forward, they might be a surrogate for the more time consuming and generally less accurate estimates of severity. There are various different types of incidence-severity relationships (McRoberts et al. 2003; Seem 1984), and thus these need to be explored empirically on a 
pathosystem-specific basis. Currently, there are no data on incidence severity relationships in pecan scab, although these have been established in several other annual and perennial crop pathosystems (Carisse et al. 2013; Dillard and Seem 1990; Groth et al. 1999; James and Shih 1973; Pataky and Headrick 1988; Paul et al. 2005; Seem and Gilpatrick 1980; Silva-Acuña et al. 1999; Xu and Madden 2002).
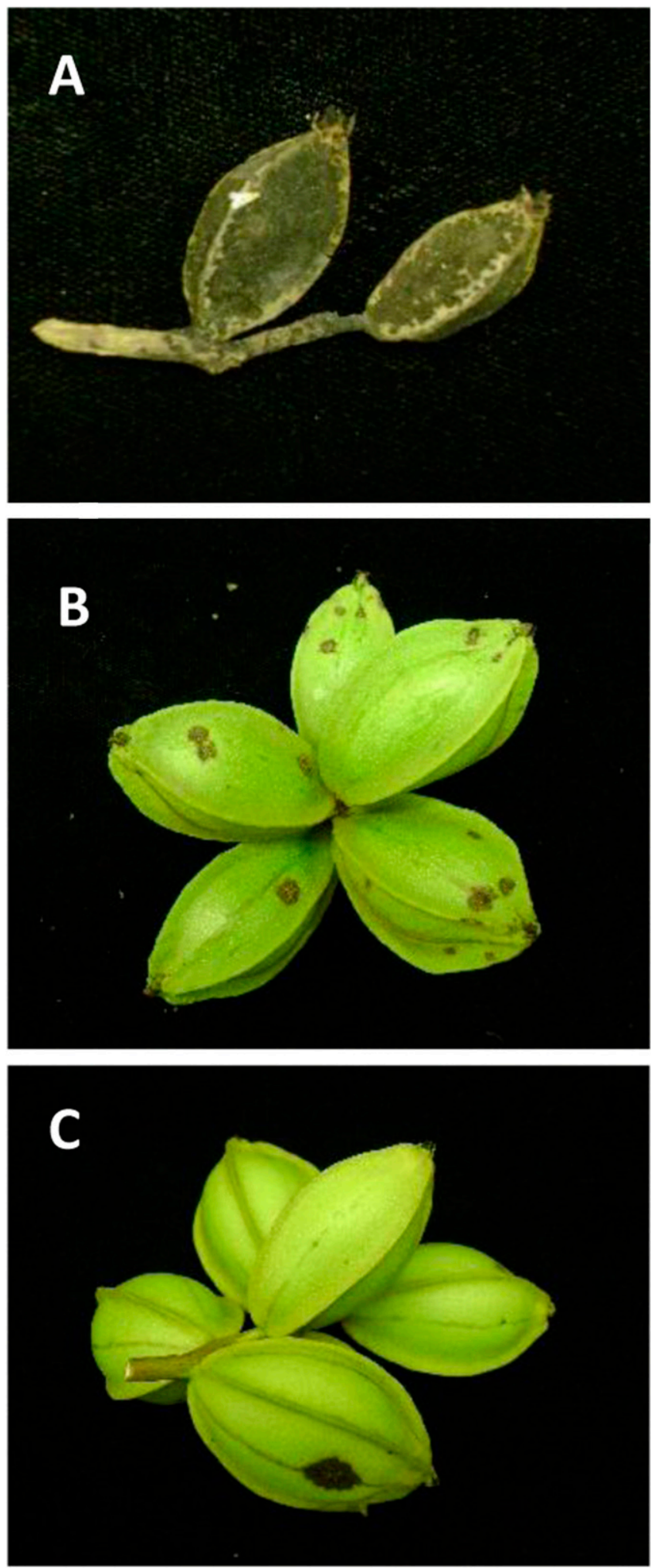

Fig. 1. Pecan fruit with contrasting scab severity and incidence of scab illustrating, $\mathbf{A}$, the effect of scab causing a severity of $\sim 100 \%$, with $\sim 100 \%$ incidence, and $\mathbf{B}$, a low severity yet high incidence $(-100 \%)$ of infected fruit, and C, a low incidence and low severity of diseased fruit.
With pecan, $V$. effusa infects the leaflets of the pinnately compound leaves, fruit, and shoots (twigs), so there are different organs on which these measures can be compared (leaflets, leaves, fruit, and shoots), and different scales on which disease might be assessed (the orchard, block or plot, tree, terminal, leaf, leaflet, fruit, or shoot). The number of leaflets per compound leaf can vary among cultivars. As with other pathosystems, this can lead to relationships in disease intensity that are measured at different scales in the spatial hierarchy (Chuang and Jeger 1987; Hughes et al. 1997; Madden and Hughes 1999; Paul et al. 2005; Seem 1984; Turechek and Madden 2003; Xu and Madden 2002). Furthermore, verification of the relationship for season, environment, growing conditions, location, and/or cultivar is recommended to ensure that the model that is selected is the most consistent and robust (Carisse et al. 2013; Paul et al. 2005; Seem and Gilpatrick 1980; Seem et al. 1981). Depending on cultivar susceptibility, pecan can suffer from particularly severe scab, covering $\sim 100 \%$ of the fruit surface and causing disease on all fruit in a tree, particularly if untreated, although it can typically also occur at high incidence and low severity, and low incidence and low severity (Fig. 1). Previous work has demonstrated the high severity of scab that can develop on fruit (Bertrand and Brenneman 2001; Gottwald and Bertrand 1983; Hunter 1983).

The aim of this study was to begin to explore the possibility of developing incidence-based methods to assess pecan scab that might be used to assess the disease in the field more rapidly (while maintaining accuracy) than estimating scab severity. Thus, the specific objectives were to i) characterize the relationship between severity and incidence of pecan scab on different organs at the scale of a tree, ii) explore any differences in relationships between incidence and severity on fruit, leaves, and leaflets, and iii) determine if there were significant effects of cultivar or sample year, and characterize the actual magnitude of those differences to determine if they were of relevance in practice.

\section{Materials and Methods}

Orchards and orchard management. Data were collected between 2010 and 2014 from 13 different orchards in Georgia, USA (some used in multiple years). Of these, three were commercial orchards and the remainder were experimental orchards located at the Southeastern Fruit and Tree Nut Research Laboratory (SEFTNRL) in Byron, GA. Orchards were comprised either of single cultivars or mixtures of cultivars and ranged in age from approximately 14 to 50 years, with tree heights from approximately $7 \mathrm{~m}$ to $20 \mathrm{~m}$. The commercial orchards received standard management practices as outlined in the GA Pecan Spray Guide (Wells 2015). Orchards at the SEFTNRL received various treatments ranging from standard management practice to unmanaged, and thus received various different fungicide regimes, fungicide types, or no fungicide to control scab.

Weather data including daily rainfall $(\mathrm{mm})$ and number of rain days for each of the seasons for the period 1 May to 30 September was obtained for the Byron, Peach Co. location (latitude 32.65755 $\mathrm{N}$, longitude $-83.73745 \mathrm{~W}$, elevation $149 \mathrm{~m}$ ) from the University of Georgia Weather Network (http://www.georgiaweather.net/index. php). Pecan production in other areas of Georgia has similar annual weather patterns.

Sample collection and disease assessments. Scab intensity was assessed on trees of nine different cultivars and four seedling trees (Table 1). The susceptibility of the cultivars to scab is wellestablished (https://cgru.usda.gov/carya/pecans/pecalph.htm). Although often the case, scab intensity on both fruit and foliage was not necessarily assessed in the same orchards. Totals of 1,972 and 1,129 trees were assessed for incidence and severity of fruit scab and foliar scab, respectively. Of these trees, 'Desirable' accounted for the greatest number of trees ( 936 and 518 assessed for scab on fruit and leaves, respectively). Cultivars 'Apache', 'Cheyenne', 'Desirable', 'Pawnee', 'Schley', 'Stuart', and 'Wichita' each also accounted for $>60$ trees sampled for both fruit and foliage (whole, pinnate leaves). Cultivar 'Mahan' had the fewest samples, with only two trees sampled. More than one sample was taken in some orchards during a season, representing an early and late assessment of scab on 
both fruit and foliage. The early foliage and fruit samples were taken in June to July, and July to August, respectively, and the late samples in July to October, and September to October, respectively. Due to tree height, samples were collected from the canopy of trees in all orchards using a hydraulic platform-lift. Totals of 37,461 fruit, 24,257 leaves, and 285,414 leaflets were individually sampled and assessed for scab. All samples were assessed so as to eventually be compared at the scale of a tree (on a per tree basis). Sample size for both fruit and leaves ranged from 10 to 100 fruit or leaves per tree depending on the orchard or experiment. Each fruit or leaf sample was collected arbitrarily from different terminals around the canopy of the tree, collecting leaves from arbitrary positions on a terminal.

Different raters assessed scab severity on the fruit and leaf samples from the different orchards and experiments in different years. The raters were each trained specifically to recognize symptoms of scab on fruit and foliage, and were trained how to estimate the percentage area diseased by performing practice assessments on samples of known severity. Thus each valve of each fruit was independently assessed for the percentage area diseased based on a visual estimate aided using a set of standard area diagrams (SADs, Yadav et al. 2013), and the average taken to obtain a severity estimate per fruit. Severity per fruit per tree was taken as the average of all severity estimates on the fruit collected in that tree. Incidence of scabbed fruit was the proportion of those fruit collected showing symptoms of scab per tree. Each leaflet on each leaf was assessed visually with the aid of SADs that has not been published (C. Bock, unpublished data), and the percentage area diseased estimated. Thus, the average severity per leaflet (and thus per leaf) was calculated as the average of all severity estimates on all leaflets collected in that tree. The incidence of scabbed leaflets was calculated as the proportion of those leaflets collected showing symptoms of scab per tree, and the incidence of scabbed leaves was the proportion of whole leaves showing symptoms of scab per tree.

Data analysis. The frequency of severities of fruit areas affected by pecan scab (\% area of fruit), the severities of leaflet and leaf areas affected by pecan scab (\% area of leaflets or leaves), and the number of leaflets per leaf sampled were calculated. Box plots (to show the median, the mean, the 25 th and 75 th percentiles, and the outliers) were generated to show the distribution of incidence (\% fruit, leaves, or leaflets diseased per tree) and severity (\% fruit, leaf, or leaflet area diseased per tree).

Incidence-severity relationship. Incidence-severity relationships were explored individually for scab on fruit, leaves, and leaflets. The relationship between incidence of infected leaves and infected leaflets was also explored. Several transformations of the incidence and severity data were tested (McRoberts et al. 2003; Xu and Madden 2002), but the complementary log-log (CLL) transformation was superior based on coefficients of determination, residual plots, and curve shape for the predicted severity against incidence plot. The CLL for incidence was calculated as CLL(I) $=\ln [-\ln (1-\mathrm{I})]$, where $\mathrm{I}$ is the incidence, and $\ln$ is the natural logarithm. The CLL for severity was calculated as CLL(S) $=\ln [-\ln (1-S)]$, where $S$ is the severity, and $\ln$ as already described. Prior to calculating these transformations, the data were converted to proportions, a necessity for this transformation. Furthermore, all $0 \%$ data were removed from the analysis, as there can be no relationship at $0 \%$ disease, and all $100 \%$ data points were converted to $99 \%$, as the CLL transformation can exhibit numerical instability at values close to 1 . The transformed data for incidence and severity for fruit, leaves, and leaflets were analyzed using linear regression analysis. A $t$ test was used to determine whether the slope or intercept differed from 1 or 0 , respectively. The fit of the regression model was determined using the statistics and plots described above, as well as the $\mathrm{F}$ and $P$ values of the general linear model (GLM) procedure invoked for the analysis. The CLL data were back-transformed to $(1-\exp [-\exp (\mathrm{CCL})])$ compare predicted severity values across different levels of incidence among cultivars and years to assess actual magnitude of differences among regressions. All analyses were performed in SAS V9.4 (SAS Institute, Cary, NC).

Analysis of cultivar and year effects. To determine the effects of cultivar or year on the I-S relationships, the data were subjected to an analysis of covariance (ANCOVA) in order to compare slope and intercept parameter estimates among years and cultivars. All data were included in the analysis of year effects, but only those cultivars with sufficient data for fruit, leaves, and leaflets (i.e., $>60$ trees, 'Apache', 'Cherokee', 'Cheyenne', 'Desirable', 'Pawnee', 'Stuart', 'Schley')

Table 1. Source of trees from which fruit, leaflets, and leaves were assessed for incidence and severity of pecan scab caused by Venturia effusa

\begin{tabular}{|c|c|c|c|c|c|c|c|}
\hline \multirow[b]{2}{*}{ Plant organ } & \multirow[b]{2}{*}{ Cultivar } & \multicolumn{5}{|c|}{ Year } & \multirow[b]{2}{*}{ Total } \\
\hline & & 2010 & 2011 & 2012 & 2013 & 2014 & \\
\hline \multirow[t]{11}{*}{ Fruit } & Apache & $36(2)^{\mathrm{a}}$ & $38(2)$ & $30(2)$ & $0(0)$ & $0(0)$ & $104(6)$ \\
\hline & Cherokee & $0(0)$ & $0(0)$ & $0(0)$ & $40(2)$ & $0(0)$ & $40(2)$ \\
\hline & Cheyenne & $52(4)$ & $56(4)$ & $50(4)$ & $0(0)$ & $20(2)$ & $178(14)$ \\
\hline & Desirable & $72(4)$ & $290(10)$ & $268(8)$ & $124(6)$ & $182(8)$ & $936(36)$ \\
\hline & Mahan & $0(0)$ & $0(0)$ & $2(1)$ & $0(0)$ & $0(0)$ & $2(1)$ \\
\hline & Pawnee & $0(0)$ & $0(0)$ & $0(0)$ & $35(1)$ & $70(2)$ & $105(3)$ \\
\hline & Schley & $0(0)$ & $32(2)$ & $36(2)$ & $32(0)$ & $64(2)$ & $164(6)$ \\
\hline & Seedling ${ }^{\mathrm{b}}$ & $0(0)$ & $0(0)$ & $4(1)$ & $0(0)$ & $0(0)$ & $4(1)$ \\
\hline & Stuart & $0(0)$ & $71(1)$ & $170(2)$ & $0(0)$ & $66(1)$ & $307(4)$ \\
\hline & Wichita & $36(2)$ & $50(4)$ & $46(4)$ & $0(0)$ & $0(0)$ & $132(10)$ \\
\hline & Total & $196(12)$ & $537(23)$ & $606(24)$ & $231(9)$ & $402(15)$ & $1,972(83)$ \\
\hline \multirow[t]{11}{*}{ Leaves and leaflets } & Apache & $18(1)$ & $19(1)$ & $15(1)$ & $15(1)$ & $0(0)$ & $67(4)$ \\
\hline & Cherokee & $0(0)$ & $0(0)$ & $0(0)$ & $20(1)$ & $0(0)$ & $20(1)$ \\
\hline & Cheyenne & $26(2)$ & $28(2)$ & $25(2)$ & $0(0)$ & $10(1)$ & 89 (7) \\
\hline & Desirable & $46(3)$ & $145(5)$ & 134 (4) & $85(4)$ & $108(4)$ & $518(20)$ \\
\hline & Mahan & $0(0)$ & $0(0)$ & $1(1)$ & $0(0)$ & $0(0)$ & $1(1)$ \\
\hline & Pawnee & $0(0)$ & $0(0)$ & $0(0)$ & $35(2)$ & $35(1)$ & $70(3)$ \\
\hline & Schley & $0(0)$ & $16(1)$ & $18(1)$ & $32(1)$ & $32(1)$ & $98(4)$ \\
\hline & Seedling & $0(0)$ & $0(0)$ & $2(1)$ & $0(0)$ & $0(0)$ & $2(1)$ \\
\hline & Stuart & $0(0)$ & $0(0)$ & $85(1)$ & $0(0)$ & $42(2)$ & $127(3)$ \\
\hline & Wichita & $18(1)$ & $33(3)$ & $31(2)$ & $35(2)$ & $20(1)$ & $137(9)$ \\
\hline & Total & $108(7)$ & $241(12)$ & $311(13)$ & $222(11)$ & $247(10)$ & $1,129(53)$ \\
\hline
\end{tabular}

\footnotetext{
${ }^{a}$ Each number represents the count of trees assessed. The number in parentheses represents the number of different assessment events (fields, or assessments in the same field). Trees having zero values were removed from the analysis, resulting in a total of 1,863 used for the assessment of scab on fruit, and 899 trees for the assessments of scab on leaves and leaflets.

b A native or "seedling" tree, with each tree having a unique genotype.
} 
were included when exploring the effects of cultivar. The interactions of cultivar and year with CLL(I) were evaluated and if significant, separate slopes and intercepts were estimated individually for each cultivar and year. Here, we used SAS PROC GLM for testing of more general ANCOVA models that include separate slope (and intercept) parameters for different treatments. Also, we used the modern data analysis tool, SAS PROC MIXED (e.g., Littell et al. 1996; Madden et al. 2007), in order to compare the results.

\section{Results}

Severity of scab on individual fruit, leaves, and leaflets. Based on the samples in this study, the frequency of scab severity followed a different distribution on fruit compared with leaves and leaflets (Fig. $2 \mathrm{~A}-\mathrm{C})$. Although there was a high frequency of disease-free fruit (18.8\% of those sampled), all severities from 0 to $100 \%$ area diseased were represented, with $9.9 \%$ of fruit having $100 \%$ fruit area diseased. Similarly, $51.9 \%$ of leaves sampled had no disease, but the severity of disease very rarely exceeded $10 \%$ on leaves. Only $0.3 \%$ of all leaves had a severity $>10 \%$, and none had a severity $>39.3 \%$ area diseased. Of the individual leaflets, although $74.6 \%$ had no scab, only very few had scab severity $>5 \%$ ( $1.4 \%$ of leaflets). A very few ( 32 leaflets, or $0.01 \%$ ) had a severity of $100 \%$.

Mean incidence and severity of scab on individual trees. There were insufficient samples taken from cultivar 'Mahan' or the native seedlings to make observations ( $\leq 4$ trees), but trees of the remaining cultivars developed a high incidence and severity of scab on fruit (Fig. 3A and B), a moderate incidence, but low severity on whole compound leaves (Fig. 3C and D), and a moderate to low incidence, but low severity on leaflets (Fig. 3E and F). On trees of these remaining cultivars, the mean incidence and severity on fruit were 68.4 to $100 \%$ and $5.9-77.8 \%$, respectively; on leaves the mean incidence and severity were $36.0-57.1 \%$ and $0.17-1.09 \%$, respectively; and on leaflets the mean incidence and severity were $16.5-49.7 \%$ and $0.17-1.09 \%$, respectively (Fig. 3 and Supplementary Table 1).

Not all cultivars or orchards were assessed in each year, but scab incidence and severity on trees did vary by year (Fig. 4). Among years, the mean incidence and severity on fruit was $64.5-98.0 \%$ and $4.9-57.0 \%$, respectively; on leaves the mean incidence and severity was $14.1-92.2 \%$ and $0.02-1.18 \%$, respectively; and on leaflets the mean incidence and severity was $2.6-66.5 \%$ and 0.02 to $1.18 \%$,
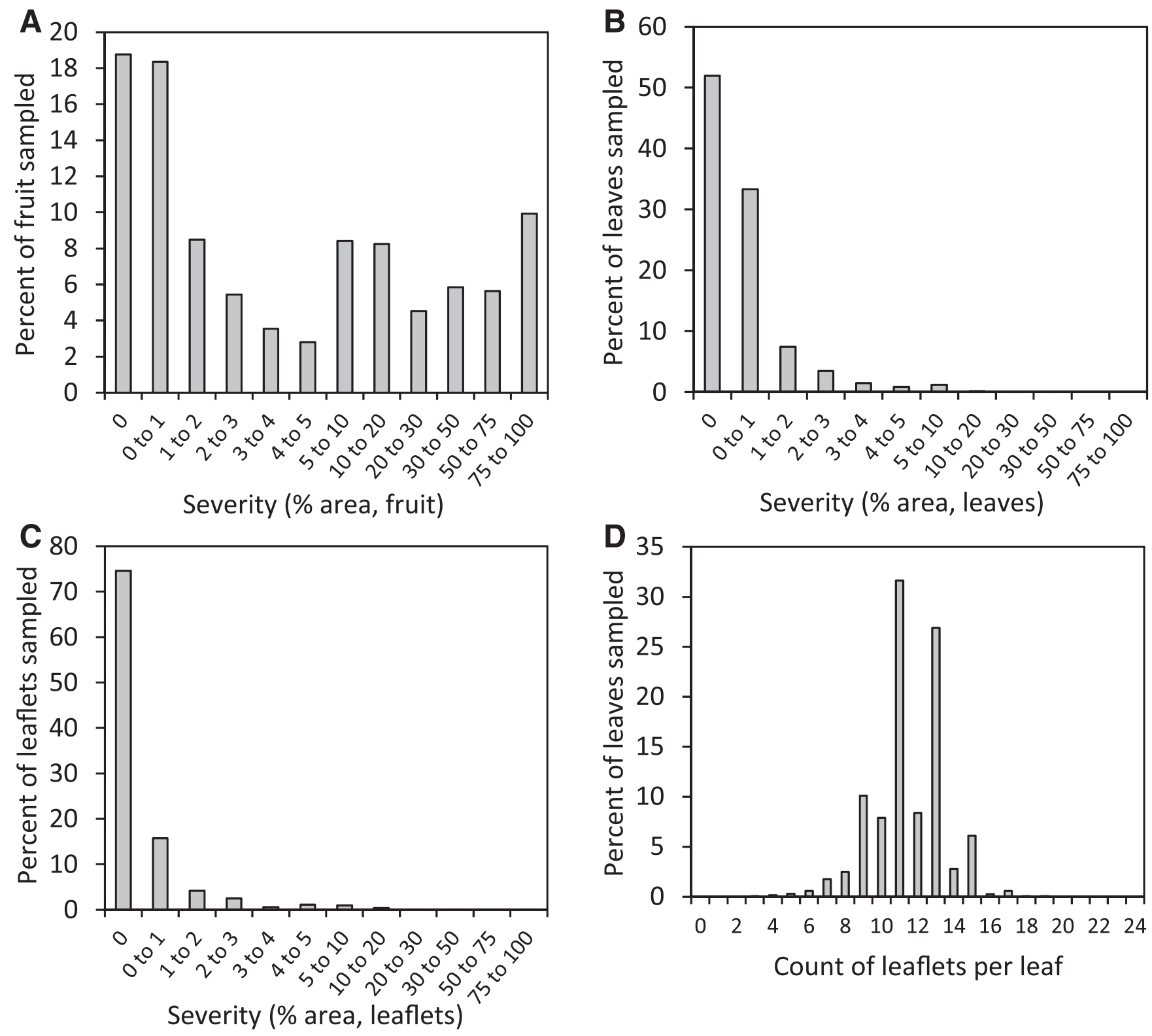

Fig. 2. The frequency of A, severities of fruit areas affected by pecan scab (\% area of fruit) caused by Venturia effusa, B, severities of leaf areas affected by pecan scab (\% area of leaves), C, severities of leaflet areas affected by pecan scab (\% area of leaflets), and D, the number of leaflets per leaf sampled (all cultivars and seedlings). 
respectively (Fig. 4 and Supplementary Table 2). Rainfall, the main driver for scab epidemics, was below average in 2011 and 2014, close to average in 2012, but above average in 2010 and 2013 (2013 was particularly wet, receiving $812 \mathrm{~mm}$ of rain compared with the long-term average of $404 \mathrm{~mm}$ ) (Supplementary Fig. 1).

Relationship between incidence and severity of scab on fruit. Over all trees, the relationship between CLL(I) and CLL(S) was linear (Fig. 5A and B, and Table 2), and was moderately strong, as indicated by the coefficient of variation $\left(\mathrm{R}^{2}=0.61\right.$, slope $\left(\beta_{1}\right)=$ 1.726, intercept $\left.\left(\beta_{0}\right)=-4.512\right)$. The interactions between cultivar and CLL(I) $(\mathrm{F}=3.3, P=0.003)$, and year and CLL(I) $(\mathrm{F}=21.8$,

$P<0.0001)$ were significant; therefore, slopes and intercepts for the I-S relationships were estimated separately for each cultivar and year. Both SAS PROC GLM and MIXED procedures were used for this
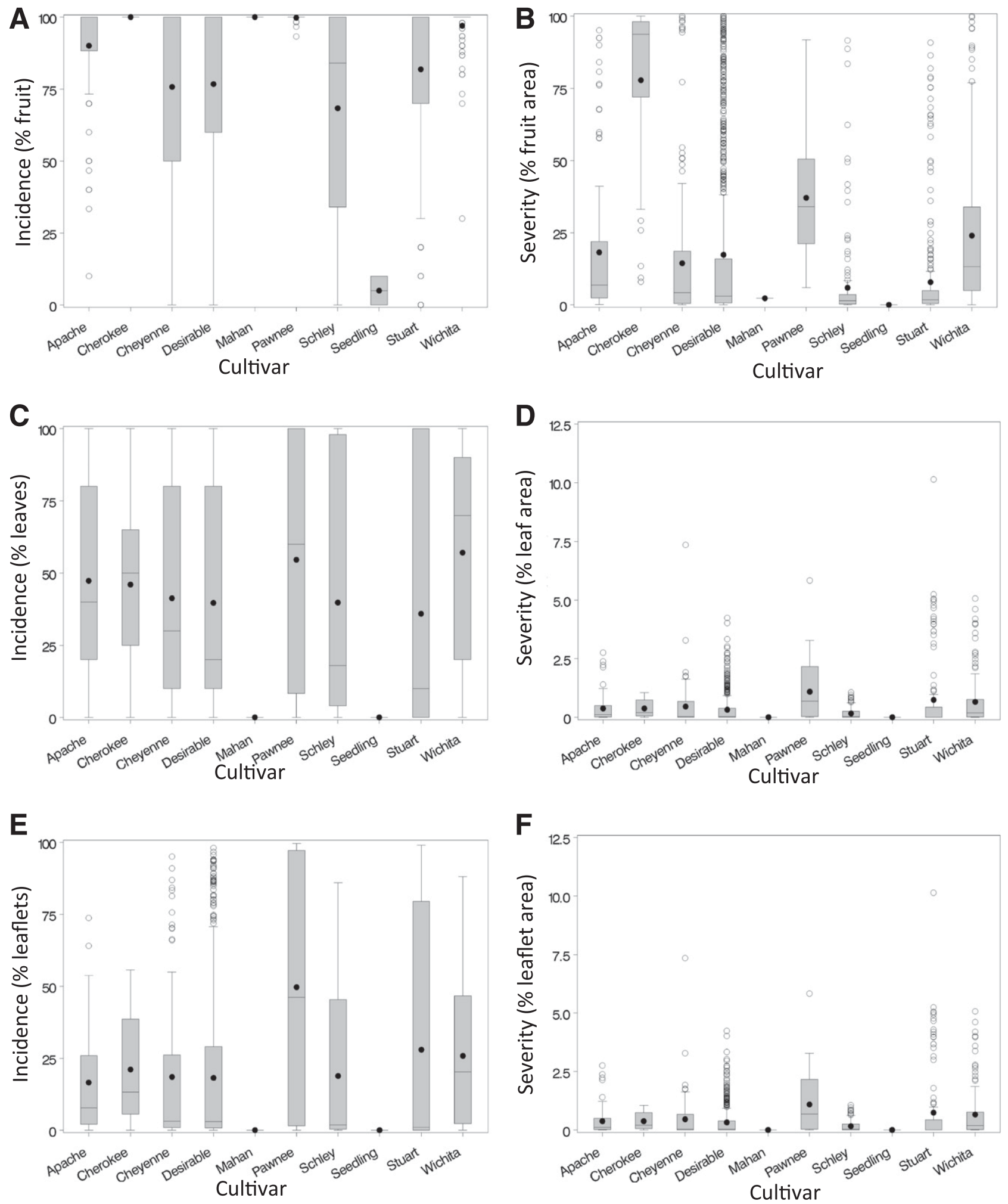

Fig. 3. Box plots showing the distribution of incidence (\% units diseased per tree, A, C, E) and severity (\% unit area diseased per tree, B, D, F) for pecan scab caused by Venturia effusa for A, B, fruit, C, D, leaves (i.e., a compound leaf), and E, F, leaflets on different cultivars and seedlings. The solid line in the box represents the median, the black dots the mean, the upper and lower limits of the boxes represent the 25th and 75th percentiles of the data, respectively, and the white dots represent outliers. 
analysis, and results were the same in either case. Among cultivars, with the exception of 'Pawnee' $\left(\mathrm{R}^{2}=0.12\right)$ and 'Wichita' $\left(\mathrm{R}^{2}=\right.$ 0.38 ), the linear regression accounted for more than half of the variation $\left(R^{2}=0.54 \leq \mathrm{R} 2 \leq 0.74\right)$. Both 'Pawnee' and 'Wichita' had a preponderance of trees with $100 \%$ incidence of fruit scab, with a consistently high but wide range of severity at that incidence (Fig. 3) and very few trees with low or moderate incidence and severity. Trees of all the cultivars in this analysis showed a tendency to develop a high incidence of scab on fruit, even when severity was low (Fig. 3).

The linear regression provided a model that explained the data for all cultivars $(P \leq 0.0003$, Table 2$)$. The slope parameter $\left(\beta_{1}\right)$ had a narrow range for most cultivars (1.406 to 1.870), except 'Pawnee' (3.917) and 'Wichita' (2.455), likely affected by the consistently high incidence of scab in these two cultivars. Intercepts $\left(\beta_{0}\right)$ ranged from -4.347 ('Desirable') to -6.830 ('Pawnee').
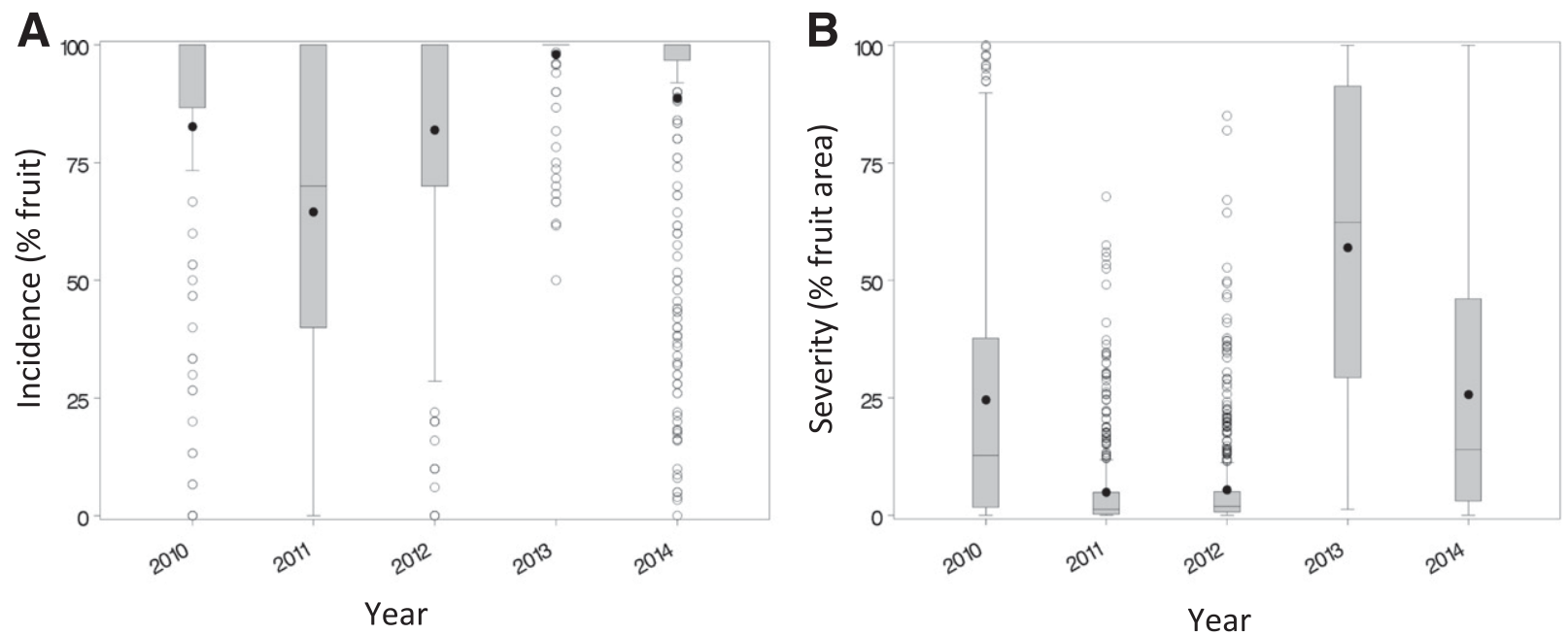

C

D
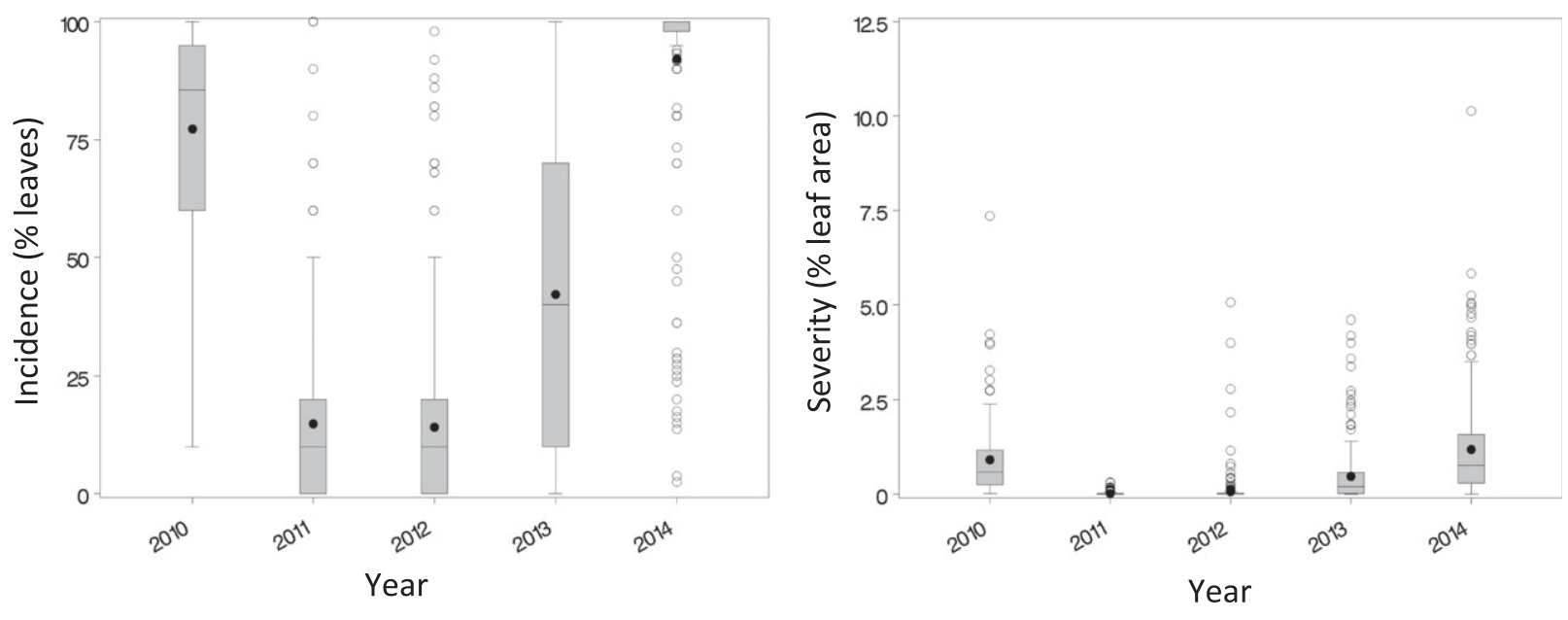

$\mathbf{E}$

$\mathbf{F}$
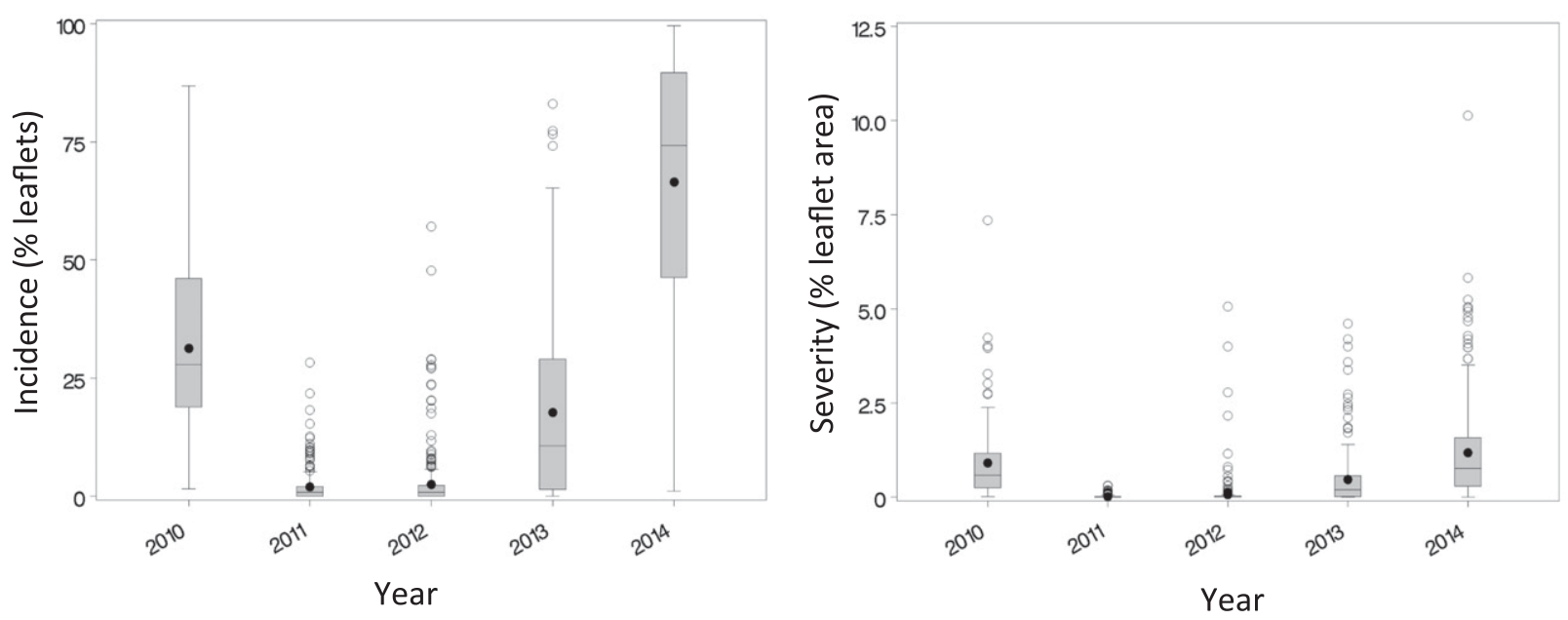

Fig. 4. Box plots showing the distribution of incidence (\% units diseased per tree, A, C, E) and severity (\% unit area diseased per tree, B, D, F) for pecan scab caused by Venturia effusa for A, B, fruit, C, D, leaves (i.e., a compound leaf), and E, F, leaflets in different years (2010-2014) on all cultivars and seedlings. The solid line in the box represents the median, the black dots the mean, the upper and lower limits of the boxes represent the 25th and 75th percentiles of the data, respectively, and the white dots represent outliers. 
Among years, with the exception of $2013\left(R^{2}=0.27\right)$, the linear regression accounted for more than half of the variation $\left(\mathrm{R}^{2}=\right.$ $0.56 \leq \mathrm{R} 2 \leq 0.73$ ). The season in 2013 was particularly wet with a consistently high incidence of scabbed fruit (Fig. 4). The linear regression models provided a significant fit for all years $(P<0.0001$, Table 2$)$. The slope parameter $\left(\beta_{1}\right)$ had a narrow range for most years
(1.269 to 1.964$)$, except 2013 (2.463), as noted already a particularly wet year. Intercepts $\left(\beta_{0}\right)$ ranged from -3.902 (2013) to -4.998 (2012).

Relationship between incidence and severity of scab on leaves. Over all trees, the relationship between CLL(I) and CLL(S) was linear (Fig. 5C and D, and Table 3) and explained most of the variation
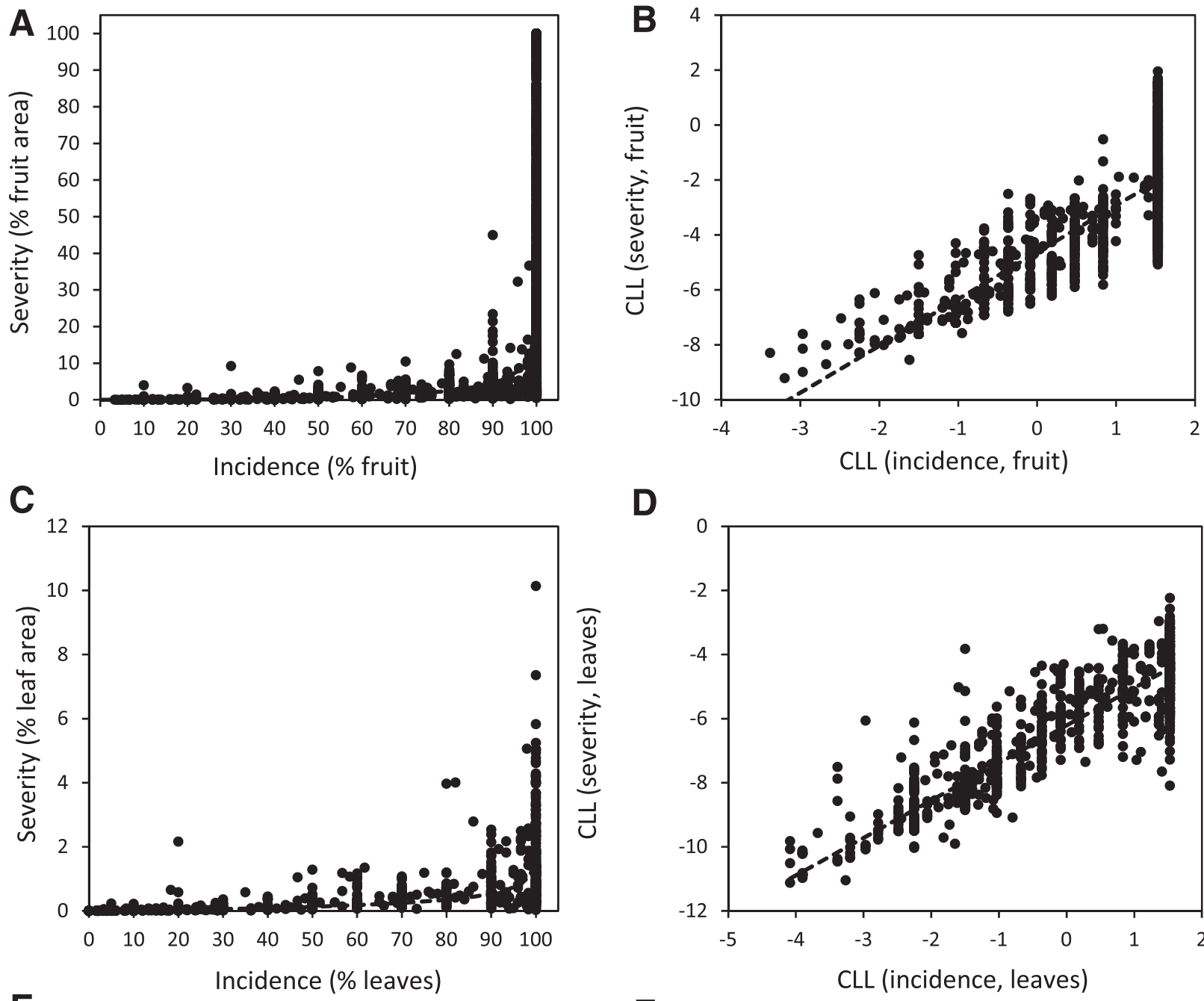

D
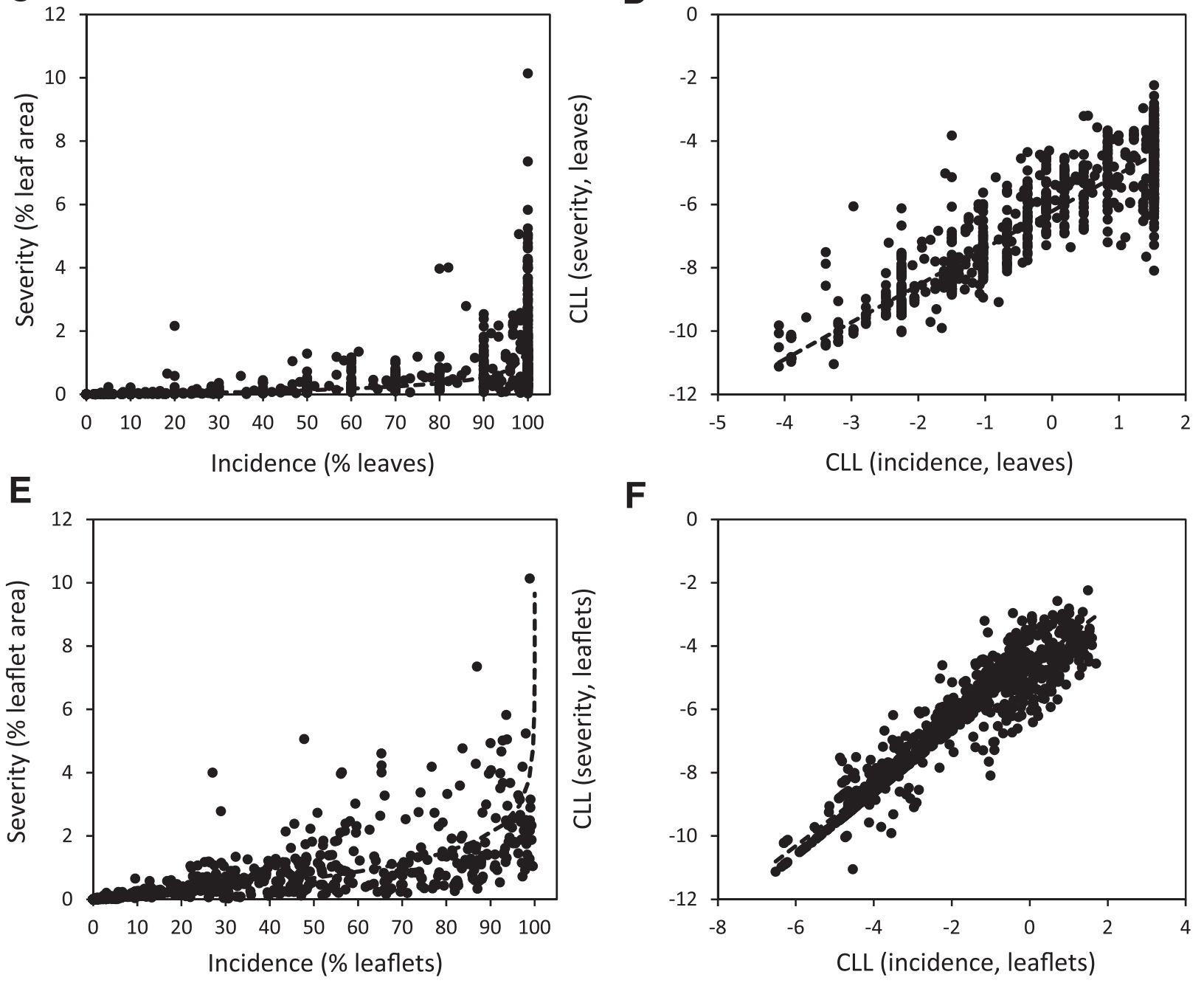

Fig. 5. The relationship between incidence and severity of pecan scab caused by Venturia effusa for different plant organs. A, C, and E are the untransformed values of incidence and severity for each tree. B, D, and F are the complementary log-log (CLL) transformed values of incidence and severity for each tree. A and B represent scab on fruit per tree, C and $\mathbf{D}$ represent scab on whole leaves per tree, and $\mathbf{E}$ and $\mathbf{F}$ represent scab on leaflets per leaf per tree. Dashed lines represent the back-transformed severity values (A, C, E) or CLL-transformed severity values (B, D, F) as predicted by the regression solutions. The statistics for the regression solution for scab on fruit, leaves, and leaflets are provided in the row 'All' in Tables 2, 3, and 4, respectively. 
Table 2. The relationship between the complementary log-log transformed incidence and severity data for pecan scab on fruit per tree caused by Venturia effusa from multiple years and cultivars ${ }^{\mathrm{a}}$

\begin{tabular}{|c|c|c|c|c|c|c|c|}
\hline Variable & Variable category & Obs & $\beta_{0}(\mathbf{S E})^{\mathbf{b}}$ & $\beta_{1}(\mathbf{S E})^{\mathbf{b}}$ & $\mathbf{R}^{2 \mathbf{b}}$ & $\mathbf{M S E}^{\mathbf{b}}$ & F-value $(P \text { value })^{b}$ \\
\hline \multirow[t]{7}{*}{ Cultivar } & Apache & 104 & $-4.700(0.225)$ & $1.870(0.170)$ & 0.54 & 1.296 & $121.1(<0.0001)$ \\
\hline & Cheyenne & 150 & $-4.551(0.133)$ & $1.741(0.097)$ & 0.68 & 1.294 & $319.8(<0.0001)$ \\
\hline & Desirable & 896 & $-4.347(0.058)$ & $1.673(0.045)$ & 0.61 & 1.495 & $1,404.9(<0.0001)$ \\
\hline & Pawnee & 105 & $-6.830(1.584)$ & $3.917(1.044)$ & 0.12 & 0.669 & $14.1(0.0003)$ \\
\hline & Schley & 160 & $-4.831(0.084)$ & $1.406(0.067)$ & 0.74 & 1.041 & $440.4(<0.0001)$ \\
\hline & Stuart & 280 & $-5.313(0.097)$ & $1.567(0.076)$ & 0.61 & 1.198 & $431.3(<0.0001)$ \\
\hline & Wichita & 132 & $-5.253(0.394)$ & $2.455(0.278)$ & 0.38 & 1.222 & $77.8(<0.0001)$ \\
\hline \multirow[t]{5}{*}{ Year } & 2010 & 178 & $-4.313(0.162)$ & $1.964(0.114)$ & 0.63 & 1.287 & $295.9(<0.0001)$ \\
\hline & 2011 & 504 & $-4.679(0.047)$ & 1.449 (0.039) & 0.73 & 1.032 & $1,353.4(<0.0001)$ \\
\hline & 2012 & 570 & $-4.998(0.061)$ & $1.269(0.047)$ & 0.56 & 1.075 & $727.2(<0.0001)$ \\
\hline & 2013 & 221 & $-3.902(0.404)$ & $2.463(0.276)$ & 0.27 & 1.350 & $79.8(<0.0001)$ \\
\hline & 2014 & 390 & $-4.223(0.099)$ & $1.838(0.068)$ & 0.65 & 1.325 & $724.6(<0.0001)$ \\
\hline All & & 1,863 & $-4.512(0.044)$ & $1.726(0.032)$ & 0.61 & 1.453 & $2,915.6(<0.0001)$ \\
\hline
\end{tabular}

a The analysis of regression model showed that both cultivar and year had a significant interaction with incidence of scab. Therefore, individual regression analyses were performed for each cultivar and year. The analysis of regression model for cultivar testing for difference in slope, incidence: $\mathrm{F}=47.7(P<0.0001)$, cultivar: $\mathrm{F}=12.4(P<0.0001)$, and incidence $\times$ cultivar: $\mathrm{F}=3.3(P=0.003)$. The analysis of regression model for year testing for difference in slope incidence: $\mathrm{F}=1049.6(P<0.0001)$, year: $\mathrm{F}=15.3(P<0.0001)$, and incidence $\times$ year: $\mathrm{F}=21.8(P<0.0001)$.

${ }^{\mathrm{b}} \beta_{0}$ (SE) is the intercept and standard error of the intercept, respectively, and $\beta_{1}$ (SE) is the slope and standard error of the slope, respectively, for the linear regression. $\mathrm{R}^{2}$ is the coefficient of determination for the regression solution. MSE is the mean square error, and the F-value (and $P$ value) is the F-statistic for the regression analysis model.

Table 3. The relationship between the complementary log-log transformed incidence and severity data for pecan scab on leaves per tree caused by Venturia effusa from multiple years and cultivars ${ }^{\mathrm{a}}$

\begin{tabular}{|c|c|c|c|c|c|c|c|}
\hline Variable & Variable category & Obs & $\boldsymbol{\beta}_{0}(\mathbf{S E})^{\mathbf{b}}$ & $\boldsymbol{\beta}_{1}(\mathbf{S E})^{\mathbf{b}}$ & $\mathbf{R}^{2 \mathbf{b}}$ & $\mathbf{M S E}^{\mathbf{b}}$ & F-value $(P \text { value })^{b}$ \\
\hline \multirow[t]{7}{*}{ Cultivar } & Apache & 60 & $-6.096(0.125)$ & $1.164(0.105)$ & 0.68 & 0.925 & $123.6(<0.0001)$ \\
\hline & Cheyenne & 67 & $-6.108(0.093)$ & $1.365(0.070)$ & 0.86 & 0.740 & $384.3(<0.0001)$ \\
\hline & Desirable & 395 & $-6.324(0.041)$ & $1.197(0.028)$ & 0.83 & 0.791 & $1,888.3(<0.0001)$ \\
\hline & Pawnee & 68 & $-5.453(0.104)$ & $1.127(0.050)$ & 0.89 & 0.838 & $518.5(<0.0001)$ \\
\hline & Schley & 89 & $-6.745(0.062)$ & $0.949(0.027)$ & 0.93 & 0.520 & $1,199.7(<0.0001)$ \\
\hline & Stuart & 73 & $-6.300(0.106)$ & $1.273(0.060)$ & 0.87 & 0.906 & $457.8(<0.0001)$ \\
\hline & Wichita & 129 & $-6.112(0.081)$ & $1.208(0.058)$ & 0.77 & 0.912 & $428.9(<0.0001)$ \\
\hline \multirow[t]{5}{*}{ Year } & 2010 & 108 & $-5.882(0.082)$ & $1.177(0.084)$ & 0.65 & 0.722 & $195.9(<0.0001)$ \\
\hline & 2011 & 158 & $-6.957(0.064)$ & $0.953(0.035)$ & 0.83 & 0.397 & $761.9(<0.0001)$ \\
\hline & 2012 & 186 & $-6.254(0.098)$ & $1.219(0.053)$ & 0.75 & 0.683 & $539.2(<0.0001)$ \\
\hline & 2013 & 201 & $-5.595(0.062)$ & $1.209(0.037)$ & 0.84 & 0.778 & $1,057.9(<0.0001)$ \\
\hline & 2014 & 246 & $-6.566(0.110)$ & $1.244(0.077)$ & 0.52 & 0.999 & $262.8(<0.0001)$ \\
\hline All & & 899 & $-6.208(0.030)$ & $1.170(0.018)$ & 0.82 & 0.861 & $4,085.3(<0.0001)$ \\
\hline
\end{tabular}

a The analysis of regression model showed that both cultivar and year had a significant interaction with incidence of scab. Therefore, individual regression analyses were performed for each cultivar and year. The analysis of regression model for cultivar testing for difference in slope, incidence: $\mathrm{F}=2804.1(P<0.0001)$, cultivar: $\mathrm{F}=14.9(P<0.0001)$, and incidence $\times$ cultivar: $\mathrm{F}=6.6(P<0.0001)$. The analysis of regression model for year testing for difference in slope incidence: $\mathrm{F}=1604.6(P<0.0001)$, year: $\mathrm{F}=38.1(P<0.0001)$, and incidence $\times$ year: $\mathrm{F}=3.4(P=0.009)$.

${ }^{b} \beta_{0}(\mathrm{SE})$ is the intercept and standard error of the intercept, respectively, and $\beta_{1}$ (SE) is the slope and standard error of the slope, respectively, for the linear regression. $\mathrm{R}^{2}$ is the coefficient of determination for the regression solution. MSE is the mean square error, and the F-value (and $P$ value) is the F-statistic for the regression analysis model.

Table 4. The relationship between the complementary log-log transformed incidence and severity data for pecan scab on leaflets per tree caused by Venturia effusa from multiple years and cultivars ${ }^{\mathrm{a}}$

\begin{tabular}{llrrrrrr}
\hline Variable & Variable category & Obs & $\boldsymbol{\beta}_{\mathbf{0}}(\mathbf{S E})^{\mathbf{b}}$ & $\boldsymbol{\beta}_{\mathbf{1}}(\mathbf{S E})^{\mathbf{b}}$ & $\mathbf{R}^{\mathbf{2} \mathbf{b}}$ & MSE $^{\mathbf{b}}$ & ${\text { F-value }(\boldsymbol{P} \text { value })^{\mathbf{b}}}^{\mathbf{b}}$ \\
\hline Cultivar & Apache & 60 & $-4.059(0.111)$ & $1.094(0.042)$ & 0.92 & 0.456 & $687.9(<0.0001)$ \\
& Cheyenne & 67 & $-4.241(0.111)$ & $1.049(0.040)$ & 0.91 & 0.571 & $689.5(<0.0001)$ \\
& Desirable & 395 & $-4.599(0.047)$ & $0.974(0.016)$ & 0.91 & 0.585 & $3,778.0(<0.0001)$ \\
& Pawnee & 68 & $-4.888(0.082)$ & $0.852(0.027)$ & 0.94 & 0.611 & $1,034.7(<0.0001)$ \\
& Schley & 89 & $-5.194(0.069)$ & $0.840(0.018)$ & 0.96 & 0.395 & $2150.3(<0.0001)$ \\
& Stuart & 73 & $-4.935(0.095)$ & $0.923(0.032)$ & 0.92 & 0.698 & $819.8(<0.0001)$ \\
& Wichita & 129 & $-4.366(0.097)$ & $0.988(0.037)$ & 0.85 & 0.741 & $714.9(<0.0001)$ \\
Year & 2010 & 108 & $-3.811(0.072)$ & $1.222(0.048)$ & 0.86 & 0.456 & $649.8(<0.0001)$ \\
& 2011 & 158 & $-4.570(0.086)$ & $0.983(0.021)$ & 0.93 & 0.247 & $2,211.0(<0.0001)$ \\
& 2012 & 186 & $-3.833(0.121)$ & $1.137(0.030)$ & 0.89 & 0.458 & $1,423.2(<0.0001)$ \\
& 2013 & 201 & $-3.902(0.042)$ & $1.119(0.015)$ & 0.97 & 0.353 & $5,905.4(<0.0001)$ \\
& 2014 & 246 & $-5.156(0.041)$ & $1.102(0.035)$ & 0.80 & 0.638 & $997.3(<0.0001)$ \\
All & & 899 & $-4.647(0.030)$ & $0.944(0.010)$ & 0.91 & 0.625 & $8,537.1(<0.0001)$ \\
\hline
\end{tabular}

a The analysis of regression model showed that both cultivar and year had a significant interaction with incidence of scab. Therefore, individual regression analyses were performed for each cultivar and year. The analysis of regression model for cultivar testing for difference in slope, incidence: $\mathrm{F}=5586.3(P<0.0001)$, cultivar: $\mathrm{F}=15.2(P<0.0001)$, and incidence $\times$ cultivar: $\mathrm{F}=7.8(P<0.0001)$. The analysis of regression model for year testing for difference in slope incidence: $\mathrm{F}=5203.9(P<0.0001)$, year: $\mathrm{F}=158.2(P<0.0001)$, and incidence $\times$ year: $\mathrm{F}=4.1(P<0.003)$.

${ }^{\mathrm{b}} \beta_{0}$ (SE) is the intercept and standard error of the intercept, respectively, and $\beta_{1}(\mathrm{SE})$ is the slope and standard error of the slope, respectively, for the linear regression. $\mathrm{R}^{2}$ is the coefficient of determination for the regression solution. MSE is the mean square error, and the F-value (and $P$ value) is the F-statistic for the regression analysis model. 
for all cultivars combined $\left(\mathrm{R}^{2}=0.82\right.$, slope $\left(\beta_{1}\right)=1.170$, intercept $\left.\left(\beta_{0}\right)=-6.208\right)$. The ANCOVA demonstrated significant differences among the slopes and intercepts of the linear regressions for both cultivars $(\mathrm{F}=6.6, P<0.0001$; Table 3$)$ and years $(\mathrm{F}=3.4, P=0.009$; Table 3), thus individual regression solutions are presented for the different cultivars and years. Both SAS PROC GLM and MIXED procedures were used for this analysis, and results were the same in either case. Among cultivars, the linear regression accounted for most of the variation $\left(\mathrm{R}^{2}=0.68\right.$ to 0.93$)$. The linear regression provided a model that explained the data for each cultivar $(P<0.0001$, Table 3$)$. The slope parameter $\left(\beta_{1}\right)$ had a narrow range for most cultivars $(0.949$ to 1.365$)$. Intercepts $\left(\beta_{0}\right)$ ranged from -5.453 ('Pawnee') to -6.745 ('Schley').

Among years, with the exception of $2014\left(R^{2}=0.52\right)$, the linear regression accounted for most of the variation $\left(R^{2}=0.65\right.$ to 0.84$)$. The linear regression models provided a significant fit for all years
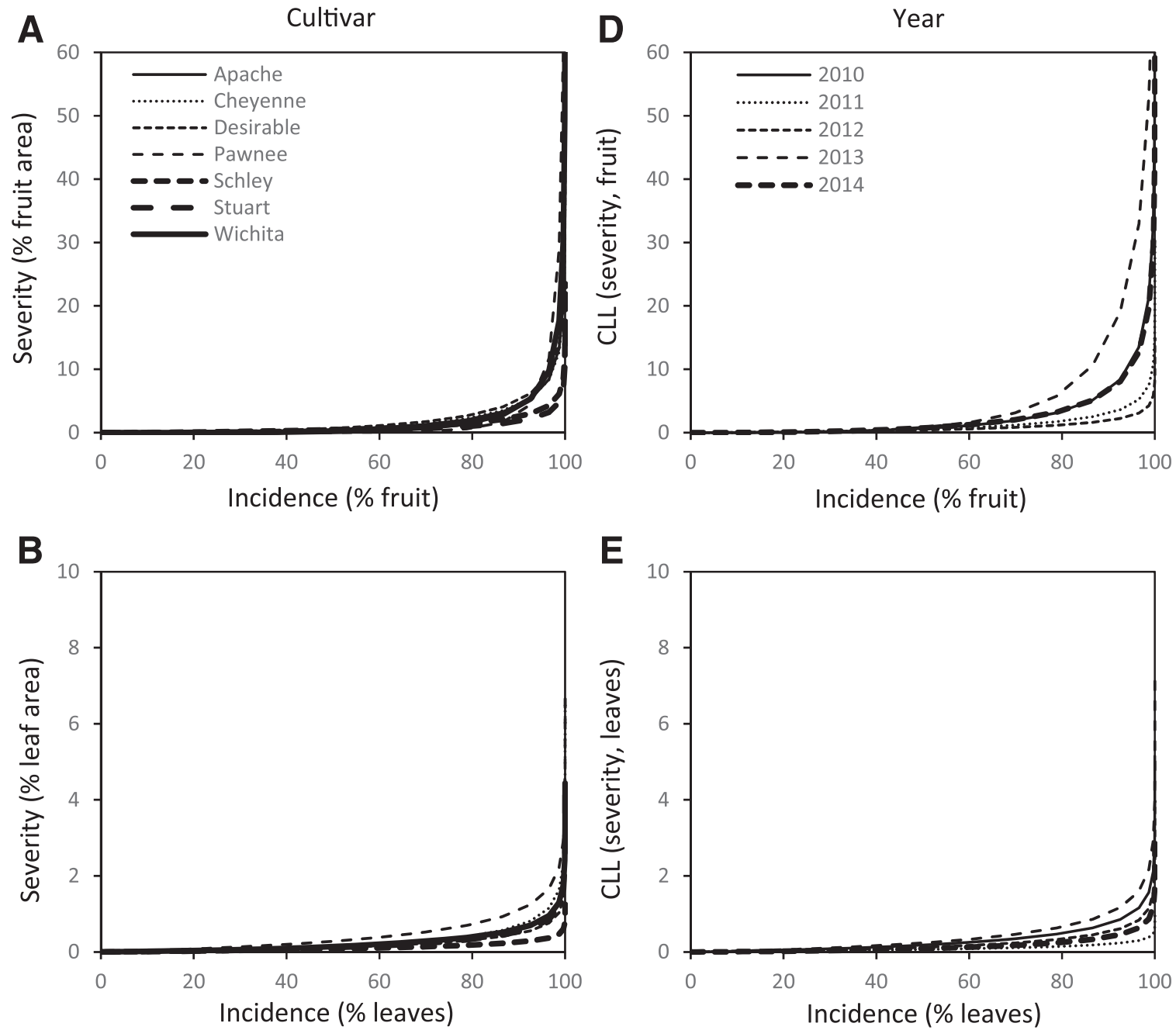

$\mathbf{E}$
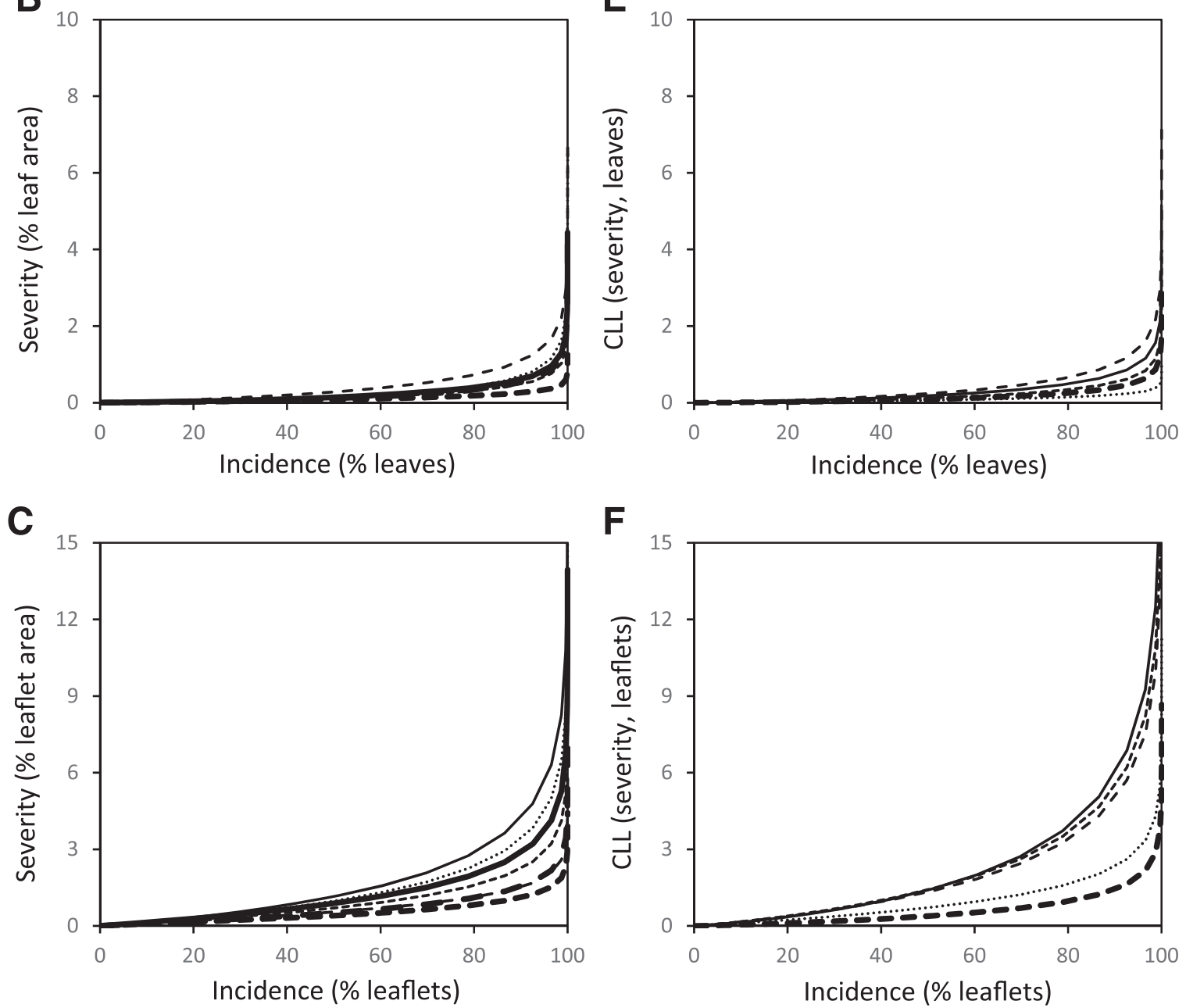

Fig. 6. The relationship between incidence and severity of pecan scab caused by Venturia effusa for fruit, leaves, and leaflets based on the back-transformed values from the models in Tables 2, 3, and 4, respectively. A, B, and $\mathbf{C}$ represent different cultivars, and $\mathbf{D}, \mathbf{E}$, and $\mathbf{F}$ represent the different years in which the relationships were compared. 
$(P<0.0001$, Table 3$)$. The slope parameter $\left(\beta_{1}\right)$ had a narrow range (0.953 to 1.244$)$. Intercepts $\left(\beta_{0}\right)$ ranged from -5.595 (2013) to -6.957 (2011)

Relationship between incidence and severity of scab on leaflets. Over all trees, the relationship between CLL(I) and CLL(S) was linear (Fig. 5E and F, and Table 4) and explained most of the variation for all cultivars combined $\left(\mathrm{R}^{2}=0.91\right.$, slope $\left(\beta_{1}\right)=0.944$, intercept $\left.\left(\beta_{0}\right)=-4.647\right)$. The ANCOVA demonstrated significant differences among the slopes and intercepts of the linear regressions for both cultivars $(\mathrm{F}=7.8, P<0.0001$; Table 4$)$ and years $(\mathrm{F}=4.1, P<0.003$; Table 4), thus individual regression solutions are presented for the different cultivars and years. Both SAS PROC GLM and MIXED procedures were used for this analysis, and results were the same in either case. Among cultivars, the linear regression accounted for most of the variation $\left(\mathrm{R}^{2}=0.85\right.$ to 0.96$)$. The linear regression provided a model that explained the data for each cultivar $(P<0.0001$, Table 3$)$. The slope parameter $\left(\beta_{1}\right)$ had a narrow range for most cultivars (0.840 to 1.094$)$. Intercepts $\left(\beta_{0}\right)$ ranged from -4.059 ('Apache') to -5.194 ('Schley').

The linear regression models provided a significant fit for all years $(P<0.0001$, Table 4$)$, and among years, the linear regression accounted for most of the variation $\left(\mathrm{R}^{2}=0.80\right.$ to 0.97$)$. The slope parameter $\left(\beta_{1}\right)$ had a narrow range $(0.983$ to 1.222$)$. Intercepts $\left(\beta_{0}\right)$ ranged from -3.811 (2010) to -5.156 (2014).

Although the analysis of regression model demonstrated significant effects of cultivar and year, inspection of the intercepts and the slopes for the fruit, leaf, and leaflet data from different cultivars and years show that the magnitude of the differences was relatively small. Furthermore, the back-formed predicted severity values across the different levels of incidence among cultivars and years (Fig. $6 \mathrm{~A}-\mathrm{F})$ demonstrate very little difference existed among cultivars and years for the I-S relationships on fruit, leaves, or leaflets. Only at high incidence (approximately 90, 90, and 75\% for fruit, leaves, or leaflets, respectively) was there discernible separation among cultivars. Similarly, only at high incidence (approximately 85, 95, and $60 \%$ for fruit, leaves, or leaflets, respectively) was there discernible separation among years. Based on the limited differences among cultivars and seasons, a single regression solution described for each plant part (fruit, leaf, and leaflet in Tables 2, 3, and 4, respectively) may be adequate to describe the relationship between incidence and severity of pecan scab at the scale of the tree. However, although all three models were appropriate for the combined data $(P<0.0001)$, the coefficients of determination demonstrated that the model was least robust for fruit $\left(\mathrm{R}^{2}=0.61\right)$ compared with leaves $\left(\mathrm{R}^{2}=0.82\right)$ or leaflets $\left(\mathrm{R}^{2}=0.91\right)$.

There was a linear relationship between CLL(I) for leaves and CLL(I) for leaflets (Fig. 7). The model was robust $(P<0.0001)$, and the regression explained most of the variation $\left(\mathrm{R}^{2}=0.91\right)$. As noted in the Materials and Methods, severity per leaf and severity per leaflet was the same, so regression analyses were not performed comparing CLL(S) for leaves versus CLL(S) for leaflets, CLL(I) for leaves versus $\mathrm{CLL}(\mathrm{S})$ for leaflets, or CLL(I) for leaflets versus CLL(S) for leaves.

\section{Discussion}

As noted in the introduction, and observed in this study, there can be extremely high severity of scab on fruit (Bertrand and Brenneman 2001; Gottwald and Bertrand 1983; Hunter 1983). We observed several untreated trees of particularly susceptible cultivars (for example, 'Wichita' and 'Cherokee') having 100\% of fruit scabbed with $100 \%$ of the fruit surface covered in disease, as illustrated in Figure 1. This was observed not only in wetter, epidemic years early in the season, but also was more common later in the season as the fruit had matured and the epidemic had peaked (some September or early October assessments). Whereas foliage is known to develop resistance to infection as it matures (Gottwald 1985; Turechek and Stevenson 1998), fruit remain susceptible to infection throughout development to harvest, although impact of disease on yield after shell hardening (late August) in thought to be negligible (Gottwald and Bertrand 1988; Stevenson and Bertrand 2001). Hence, fungicide sprays for scab are generally not applied after the first week of September.

Based on the CLL-transformed data, there were clear and significant relationships between incidence and severity for fruit, leaves, and leaflets infected with pecan scab for all cultivars (where there was sufficient data) and for all years where the relationships were tested. The CLL transformation of these data appear to provide a reasonably robust and reliable descriptor of the relationship on all three plant parts at the scale of the pecan tree. Pecan scab is the most important disease of pecan, and in many studies severity measures are taken to ascertain treatment effects or establish the impact of disease on yield. Severity estimates on the fruit or foliage are time consuming and error-prone, even when standard area diagrams are used to obtain more accurate estimates (Bock et al. 2016; Yadav et al. 2013). By characterizing the relationship between incidence and severity of scab, it was hoped to establish the utility of scab incidence as a way to quantify severity.
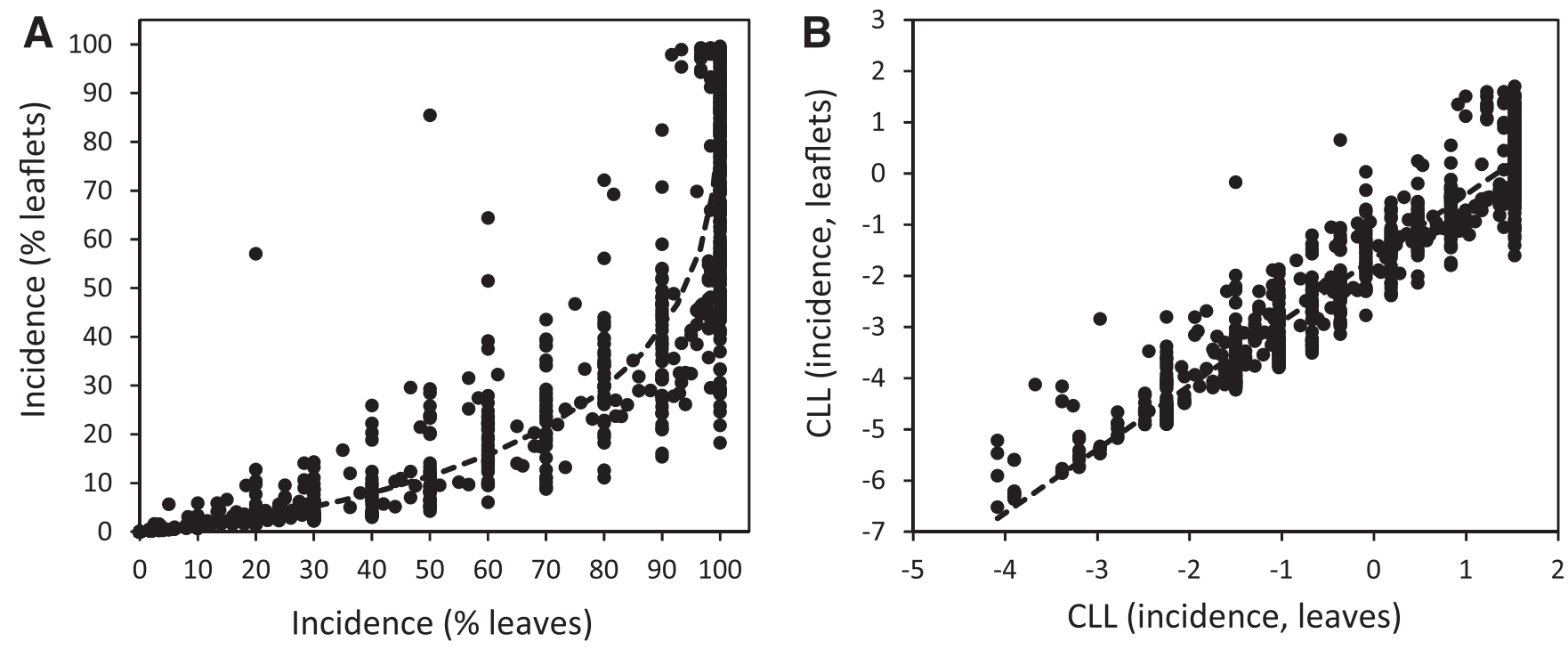

Fig. 7. The relationship between the incidence of pecan scab, caused by Venturia effusa, on leaves and leaflets. A shows the untransformed values of the incidence, and $\mathbf{B}$ shows the complementary log-log (CLL) transformed values for the incidence data for each tree. Dashed lines represent the back-transformed severity values (A) or CLL-transformed severity values $(B)$ as predicted by the regression solutions. For the transformed data intercept, $\beta_{0}(S E)=-1.652(0.021)$, slope, $\beta_{1}(S E)=1.244(0.013), R^{2}=0.91, M S E=0.603$, $\mathrm{F}=9424.8(P<0.0001)$. 
However, it was evident that severity of scab on fruit and leaves was frequently very low, even when incidence was $>85 \%$. On leaflets, this observation was less pronounced, but $100 \%$ incidence was still observed at severities of only 2 to $10 \%$. Although the model fit to the CLL-transformed data were highly significant in all cases, the relationship was least reliable on fruit $\left(\mathrm{R}^{2}=0.61\right)$, compared with leaves $\left(\mathrm{R}^{2}=0.82\right)$ or leaflets $\left(\mathrm{R}^{2}=0.91\right)$. We found that year and cultivar affected the relationship, as has been observed in other pathosystems (Carisse et al. 2013; Paul et al. 2005), although the numeric differences of the CLL transformed data were for the most part relatively small among cultivars and years, and as noted, severity was not greatly different except at high incidence of disease. Back-transformed predicted severity (Fig. 6A-F) also showed relatively small numeric differences for both cultivars and years. For example, in a tree with a $35.0 \%$ incidence of scab on fruit, the predicted severity ranged from 0.0 to $0.3 \%$, depending on cultivar, and 0.2 to $0.3 \%$, depending on year. In a tree with $89.0 \%$ incidence of scab on fruit, the predicted severity ranged from 1.5 to $4.1 \%$, depending on cultivar, and 1.6 to $10.6 \%$, depending on year. On a tree basis, with an incidence of $35.0 \%$ leaves scabbed, the predicted severity ranged from $<0.1-0.2 \%$, depending on cultivar, and $<0.1-0.1 \%$, depending on year. At $89.0 \%$ incidence of leaves with scab, the predicted severity ranged from 0.2 to $0.9 \%$, depending on cultivar, and $0.2-0.9 \%$, depending on year. Even when the incidence of scabbed leaflets was $35.0 \%$ in tree canopies, the predicted severity ranged from 0.3 to $0.7 \%$, depending on cultivar, and 0.2 to $0.8 \%$, depending on year. Moreover, at an incidence of $89.0 \%$ leaflets scabbed, the predicted severity ranged from 1.0 to $3.6 \%$, depending on cultivar, and 1.2 to $5.1 \%$, depending on year. These data demonstrate that severity of pecan scab on all organs in trees tended to remain very low until incidence approached $100 \%$. Only at incidence $>80 \%$ did severity abruptly increase.

These results approximate to earlier reports of incidence and severity measures of pecan scab (Bertrand and Brenneman 2001). In that study, on fruit, when scab incidence was $<75 \%$, severity was 2 to $6 \%$. However, at incidence $>75 \%$, severity was 15 to $33 \%$. Indeed, in our study the numeric differences among years or cultivars tended to be quite small (at most fractions to a few percent in most cases), indicating that the relationship of incidence to severity is quite robust among cultivars and seasons. But the utility of the relationship may be less when compared with some previously described pathosystem incidence-severity relationships where the severity does not remain so low until a high incidence is achieved during the epidemic (Carisse et al. 2013; James and Shih 1973; Paul et al. 2005; Seem and Gilpatrick 1980; Silva-Acuña et al. 1999; Xu and Madden 2002). Due to the persistently low severity at high incidence noted here in the pecanscab pathosystem, measuring incidence to estimate severity may be more risky despite the reasonably consistent nature of the relationship. If it is applied as a disease assessment tool, further validation would be highly recommended prior to obtaining incidence data in place of severity data.

The range of actual estimates of severity increased with incidence, the greatest range in severity occurring at close to $100 \%$ of units diseased. This has been observed in other pathosystems (Paul et al. 2005; Seem 1984). This generally indicates less precise estimates of severity with increasing incidence. As noted previously (Paul et al. 2005), this loss of precision is due, at least to some degree, to the variation inherent in any random variable ranging from 0 to 1 (Madden and Hughes 1995).

The possible need to apply fungicide treatments based on a threshold of disease risk as practiced in some other pathosystems is not a component of forecasting pecan scab risk, which relies on monitoring predicted environmental conditions (Brenneman and Bertrand 2000; Payne and Smith 2012). However, in other pathosystems disease severity may be a useful predictor of risk, and incidence data may be more easily collected (Dillard and Seem 1990; Paul et al. 2005). With pecan scab, the utility of taking incidence assessments would be for comparing treatment effects or rating germplasm in resistance screening trials.

But as noted, the observation that low severity persists until a high incidence of scab is reached during an epidemic may limit the ability of incidence data to clearly differentiate treatment effects even when based on the CLL transformation. But if found to be effective, and if used, it would reduce the labor requirements, and result in more accurate data being obtained, as incidence estimates do not tend to suffer from the same subjective biases as do estimates of severity.

\section{Acknowledgments}

The authors appreciate the expertise and input of Dr. Michael Hotchkiss on these experiments, and the technical help of Wanda Evans, Minling Zhang, and Shirley Anderson, and assistance from Andrew Hudgens, Kaylee Carlson, Jason Shipp, Sue Burrell, and Shad Stormat at the USDA-ARS-SEFTNRL.

\section{Literature Cited}

Bertrand, P. F., and Brenneman, T. B. 2001. Aerial and weather based fungicide application for pecan scab control. Proc. S. E. Pecan Growers Assoc. 94: 62-69.

Bock, C. H., Brenneman, T. B., Hotchkiss, M. W., and Wood, B. W. 2012 Evaluation of a phosphite fungicide to control pecan scab in the southeastern USA. Crop Prot. 36:58-64.

Bock, C. H., Brenneman, T. B., Wood, B. W., and Stevenson, K. L. 2017 a. Challenges of managing disease in tall orchard trees - pecan scab, a case study. CAB Reviews: Pers. Ag. Vet. Sci. Nutr. Nat. Res. 12:1-18.

Bock, C. H., Chiang, K.-S., and Del Ponte, E. M. 2016. Accuracy of plant specimen disease severity estimates: Concepts, history, methods, ramifications and challenges for the future. CAB Reviews: Pers. Ag. Vet. Sci. Nutr. Nat. Res. 11:1-13.

Bock, C. H., Gottwald, T. R., Parker, P. E., Ferrandino, F., Welham, S., van den Bosch, F., and Parnell, S. 2010b. Some consequences of using the HorsfallBarratt scale for hypothesis testing. Phytopathology 100:1030-1041.

Bock, C. H., Hotchkiss, M. W., Brenneman, T. B., Stevenson, K. L., Goff, W. D., Smith, M. W., Wells, L., and Wood, B. W. 2017c. Severity of scab and its effect on fruit weight in mechanically hedge-pruned and topped pecan trees. Plant Dis. 101:785-793.

Bock, C. H., Hotchkiss, M. W., Young, C. A., Charlton, N. D., Chakradhar, M., Stevenson, K. L., and Wood, B. W. 2017b. Population genetic structure of Fusicladium effusum, cause of pecan scab, in the southeastern United States. Phytopathology 107:607-619.

Bock, C. H., Parker, P. E., Cook, A. Z., and Gottwald, T. R. 2008. Visual rating and the use of image analysis for assessing different symptoms of citrus canker on grapefruit leaves. Plant Dis. 92:530-541.

Bock, C. H., Poole, G., Parker, P. E., and Gottwald, T. R. 2010a. Plant disease severity estimated visually, by digital photography and image analysis, and by hyperspectral imaging. Crit. Rev. Plant Sci. 29:59-107.

Brenneman, T. B., and Bertrand, P. F. 2000. Update on development of spray advisories for pecan scab. Proc. S. E. Pecan Growers Assoc. 93:59-62.

Brenneman, T. B., Bertrand, P. F., and Mullinix, B. 1999. Spray advisories for pecan scab: Recent developments in Georgia. Pages 7-14 in: The Pecan Industry: Current Situation and Future Challenges, Third National Pecan Workshop Proceedings, B. E. McCraw, E. H. Dean, and B. W. Wood, eds. USDA Agricultural Research Service. 1998-04.

Carisse, O., Lefebvre, A., Van der Heyden, H., Roberge, L., and Brodeur, L. 2013 Analysis of incidence-severity relationships for strawberry powdery mildew as influenced by cultivar, cultivar type, and production systems. Plant Dis. 97: 354-362.

Chuang, T. Y., and Jeger, M. J. 1987. Relationship between incidence and severity of banana leaf spot in Taiwan. Phytopathology 77:1537-1541.

Conner, P. J., and Stevenson, K. L. 2004. Pathogenic variation of Cladosporium caryigenum isolates and corresponding differential resistance in pecan. HortScience 39:553-557.

Dillard, H. R., and Seem, R. C. 1990. Incidence and severity relationships for common maize rust on sweet corn. Phytopathology 80:842-846.

Goff, W. D., McVay, J. R., and Gazaway, W. S. 1996:Page 222 in: Pecan production in the Southeast. Alabama Cooperative Extension System Circular ANR-459. University, Auburn, AL.

Goff, W. D., Nesbitt, M. L., and Browne, C. L. 2003. Incidence of scab and foliage condition on pecan cultivars grown without fungicide or insecticide sprays in a humid region. HortTech. 13:381-384.

Gottwald, T. R. 1985. Influence of temperature, leaf wetness period, leaf age, and spore concentration on infection of pecan leaves by conidia of Cladosporium caryigenum. Phytopathology 75:190-194.

Gottwald, T. R., and Bertrand, P. F. 1983. Effect of time of inoculation with Cladosporium caryigenum on pecan scab development and nut quality. Phytopathology 73:714-718.

Gottwald, T. R., and Bertrand, P. F. 1988. Effects of an abbreviated pecan disease control program on pecan scab disease increase and crop yield. Plant Dis. 72: 27-32.

Gottwald, T. R., and Wood, B. W. 1985. Decreased net photosynthesis and dark respiration rates of pecan fruit and foliage in response to infection by Cladosporium caryigenum. Plant Dis. 69:800-803.

Groth, J. V., Ozmon, E. A., and Busch, R. H. 1999. Repeatability and relationship of incidence and severity measures of scab of wheat caused by Fusarium graminearum in inoculated nurseries. Plant Dis. 83:1033-1038. 
Hughes, G., McRoberts, N., Madden, L. V., and Gottwald, T. R. 1997. Relationships between disease incidence at two levels in a spatial hierarchy. Phytopathology 87:542-550.

Hunter, R. E. 1983. Influence of scab on late season nut drop of pecans. Plant Dis. 67:806-807.

James, W. C., and Shih, C. S. 1973. Relationships between incidence and severity of powdery mildew and leaf rust on winter wheat. Phytopathology 63:183-187.

Littell, R. C., Milliken, G. A., Stroup, W. W., and Wolfinger, R. D. 1996. SAS system for mixed models. SAS Institute Inc., Cary, NC.

Madden, L. V., and Hughes, G. 1995. Plant disease incidence: Distributions, heterogeneity, and temporal analysis. Annu. Rev. Phytopathol. 33:529-564.

Madden, L. V., and Hughes, G. 1999. An effective sample size for predicting plant disease incidence in a spatial hierarchy. Phytopathology 89:770-781.

Madden, L. V., Hughes, G., and van den Bosch, F. 2007. The Study of Plant Disease Epidemics. American Phytopathological Society, St. Paul, MN.

McRoberts, N., Hughes, G., and Madden, L. V. 2003. The theoretical basis and practical application of relationships between different disease intensity measurements in plants. Ann. Appl. Biol. 142:191-211.

Pataky, J. K., and Headrick, J. M. 1988. Relationships between common rust incidence and severity on a susceptible and a partially resistant sweet corn hybrid. Phytopathology 78:1155-1160.

Paul, P. A., El-Allaf, S. M., Lipps, P. E., and Madden, L. V. 2005. Relationships between incidence and severity of Fusarium head blight on winter wheat in Ohio. Phytopathology 95:1049-1060.

Payne, A. F., and Smith, D. L. 2012. Development and evaluation of two pecan scab prediction models. Plant Dis. 96:1358-1364.

Rossman, A. Y., Allen, W. C., and Castlebury, L. A. 2016. New combinations of plant associated fungi resulting from the change to one name for fungi. IMA Fungus 7:1-7 http://www.imafungus.org/Issue/71/11.pdf.

Seem, R. C. 1984. Disease incidence and severity relationships. Annu. Rev. Phytopathol. 22:133-150.
Seem, R. C., and Gilpatrick, D. 1980. Incidence and severity relationships of secondary infections of powdery mildew on apple. Phytopathology 70: 851-854.

Seem, R. C., Gilpatrick, D., and Pearson, R. C. 1981. Fungicide influence on the relationship between incidence and severity of powdery mildew on apple. Phytopathology 71:947-950.

Silva-Acuña, R., Maffia, L. A., Zambolim, L., and Berger, R. D. 1999. Incidence-severity relationships in the Coffea arabica-Hemileia vastatrix. Plant Dis. 83:186-188.

Sparks, D., Yates, I. E., Bertrand, P. F., and Brenneman, T. B. 2009. The relative impacts of elevation and rainy days on the incidence of scab damage of pecan nuts in the southeastern USA. J. Hortic. Sci. Biotechnol. 84:137-142.

Stevenson, K. L., and Bertrand, P. F. 2001. Within-season dynamics of yield loss due to pecan scab fruit infections. Phytopathology 91:S85.

Stevenson, K. L., Brenneman, T. B., and Brock, J. 2015. Results of the 2014 Pecan Scab Fungicide Sensitivity monitoring program. Georgia Pecan Grow. Mag. 26(3):16, 18, 20-23.

Turechek, W. W., and Madden, L. V. 2003. A generalized linear modeling approach for characterizing disease incidence in a spatial hierarchy. Phytopathology 93:458-466.

Turechek, W. W., and Stevenson, K. L. 1998. Effects of host resistance, temperature, leaf wetness, and leaf age on infection and lesion development of pecan scab. Phytopathology 88:1294-1301.

Wells, M. L. 2014. Pecan planting trends in Georgia. HortTech. 24:475-479.

Wells, M. L. 2015. Commercial Pecan Spray Guide. UGA Extension Bulletin 841 , University of Georgia Extension.

Wood, B. W., and Bock, C. H. 2018. Influence of fungicides on gas exchange of pecan foliage. Plant Pathol. 67:265-276.

$\mathrm{Xu}, \mathrm{X} .-\mathrm{M}$., and Madden, L. V. 2002. Incidence and density relationships of powdery mildew on apple. Phytopathology 92:1005-1014.

Yadav, N. V. S., de Vos, S. M., Bock, C. H., and Wood, B. W. 2013. Development and validation of standard area diagrams to aide assessment of pecan scab symptoms on pecan fruit. Plant Pathol. 62:325-335. 